Relations industrielles

Industrial Relations

\title{
Statistiques de conciliation
}

\section{Denys Dion}

Volume 6, numéro 3, juin 1951

URI : https://id.erudit.org/iderudit/1023218ar

DOI : https://doi.org/10.7202/1023218ar

Aller au sommaire du numéro

Éditeur(s)

Département des relations industrielles de l'Université Laval

ISSN

0034-379X (imprimé)

1703-8138 (numérique)

Découvrir la revue

Citer ce document

Dion, D. (1951). Statistiques de conciliation. Relations industrielles / Industrial Relations, 6(3), 94-95. https://doi.org/10.7202/1023218ar

Tous droits réservés @ Département des relations industrielles de l’Université Laval, 1951
Ce document est protégé par la loi sur le droit d'auteur. L'utilisation des services d'Érudit (y compris la reproduction) est assujettie à sa politique d'utilisation que vous pouvez consulter en ligne.

https://apropos.erudit.org/fr/usagers/politique-dutilisation/ 
quand même important. C'est une indication que plusieurs de ceux qui sont séparés de leur emploi retournent au travail avant longtemps.

\section{Une garantie de la Loi}

Peut-on vivre dans l'oisiveté et retirer des prestations d'assurancechômage ?

C'est un des principes de la Loi d'exiger de celui qui demande des prestations qu'il prouve d'abord qu'il appartient au marché actuel de la main-d'oeuvre; qu'il a travaillé récemment un nombre de jours important dans un emploi assuré sous le régime de la Loi.

La Commission n'est pas satisfaite de savoir qu'un homme a déjà travaillé dans un passé lointain; ni qu'il vient de travailler pour une courte période.
La personne assurée, devenue sans travail, doit prouver qu'elle a contribué au moins 180 fois à la caisse d'assurance depuis deux ans. Cela veut dire qu'elle a travaillé au moins 180 jours. Des 180 contributions, il faudra qu'au moins 60 aient été versées depuis un an, ou 45 depuis six mois; i.e., que la preuve soit faite d'une substantielle et récente histoire de travail.

Le caractère saisonnier d'une grosse tranche de notre économie impose aux travailleurs, inévitablement, bien des pertes de temps. Si on y ajoute celles dues aux progrès techniques, au chômage structural, aux pénuries de matériaux, à la maladie, aux vacances légitimes, fêtes légales et religieuses, etc., on voit que l'assuré ne pourra établir son droit à prestations qu'à la suite d'une honnête assiduité au travail.

\section{Statistiques de conciliation}

Pendant les trois premiers mois de l'année courante, le Service de conciliation de la province de Québec s'est occupé de 155 cas de conciliation pour 1,959 établissements comprenant 73,747 employés dont 41,670 étaient particulièrement concernés. De ces cas, 57 étaient en voie de règlement au début de janvier 1951 et 69 à la fin de mars 1951.

Ces cas ont été soumis au Service de conciliation sous l'empire de deux lois provinciales: la Loi des relations ouvrières de Québec et la Loi des différends ouvriers de Québec.

Sous l'empire de la première Loi, 27 cas concernant 5,240 employés ont été présentés à l'occasion d'une nouvelle convention alors que 82 cas concernant 20,171 employés l'ont été à loccasion du renouvellement de la convention. Sous l'empire de la seconde Loi, un cas concernant 400 employés a été présenté à l'occasion d'urie nouvelle convention tandis que 10 cas concernant 13,417 employés l'ont été au sujet du renouvellement de la convention et 35 cas concernant 2,442 employés ont été présentés au sujet de griefs.

De ces 155 cas, présentés pendant les trois premiers mois de l'année, 86 ont été réglés, dont 54 , couvrant plus de 20,491 employés, d'une façon satisfaisante pour les parties; 6, couvrant 226 employés, d'une façon indéfini et 26 couvrant $7,325 \mathrm{em}$ ployés ont été référés à l'arbitrage.

Tous ces cas de conciliation se répartissent de la manière suivante entre les différents groupes syndicaux: La Confédération des Travailleurs Catholiques du Canada (CTCC) a soumis au service 81 cas concernant 23,566 employés, le Congrès Canadien du Travail (CCT) en a soumis 18 pour 3,910 employés; le Congrès des Métiers et du Travail, 10 cas couvrant 1,366 employés; le Congrès des Métiers et du Travail affilié à la Fédération Américaine du Travail (CMTC-FAT) 26 cas pour 8,686 employés; le Congrès Canadien du Travail affilié au Congrès des Organisations Industrielles (CCT-COI) a soumis 15 cas pour 3,510 employés, enfin les syndicats indépendants locaux ou nationaux ont soumis 5 cas concernant 632 employés. 
Enfin pour terminer, nous donnons une liste des différents sujets soumis à la conciliation et le nombre de cas dans lesquels ces sujets ont été discutés.

Salaires

Durée du travail

Congés payés

Vacances payées

Sécurité syndicale

Promotion, permutation, congédiement, licenciement

Toute la convention

Surtemps

Ancienneté

Jours fériés

Classification des tâches
Durée et renouvellement de la convention

Procédure de règlement des griefs

Garantie de conditions minima

Sécurité sociale (excepté les plans de pensions)

Garanties d'ordre juridique

Droits de la direction

Juridiction

Périodes de repos

But

Apprentissage

Dans le tableau qui suit, on trouvera une distribution des cas selon les divers groupes industriels.

\section{Denys Dion}

Différends soumis au Service de concillation du ministère du Travail de la PROVINCE DE QUÉbEC RÉPARTIS SELON LA NATURE DES ÉTABLISSEMENTS CONCERNÉS, LE NOMBRE TOTAL DE LEURS EMPLOYÉS AINSI QUE LE NOMBRE DES EMPLOYÉS IMPLIQUÉS POUR LA PÉRIOde de JANVIER À MARS 1951.

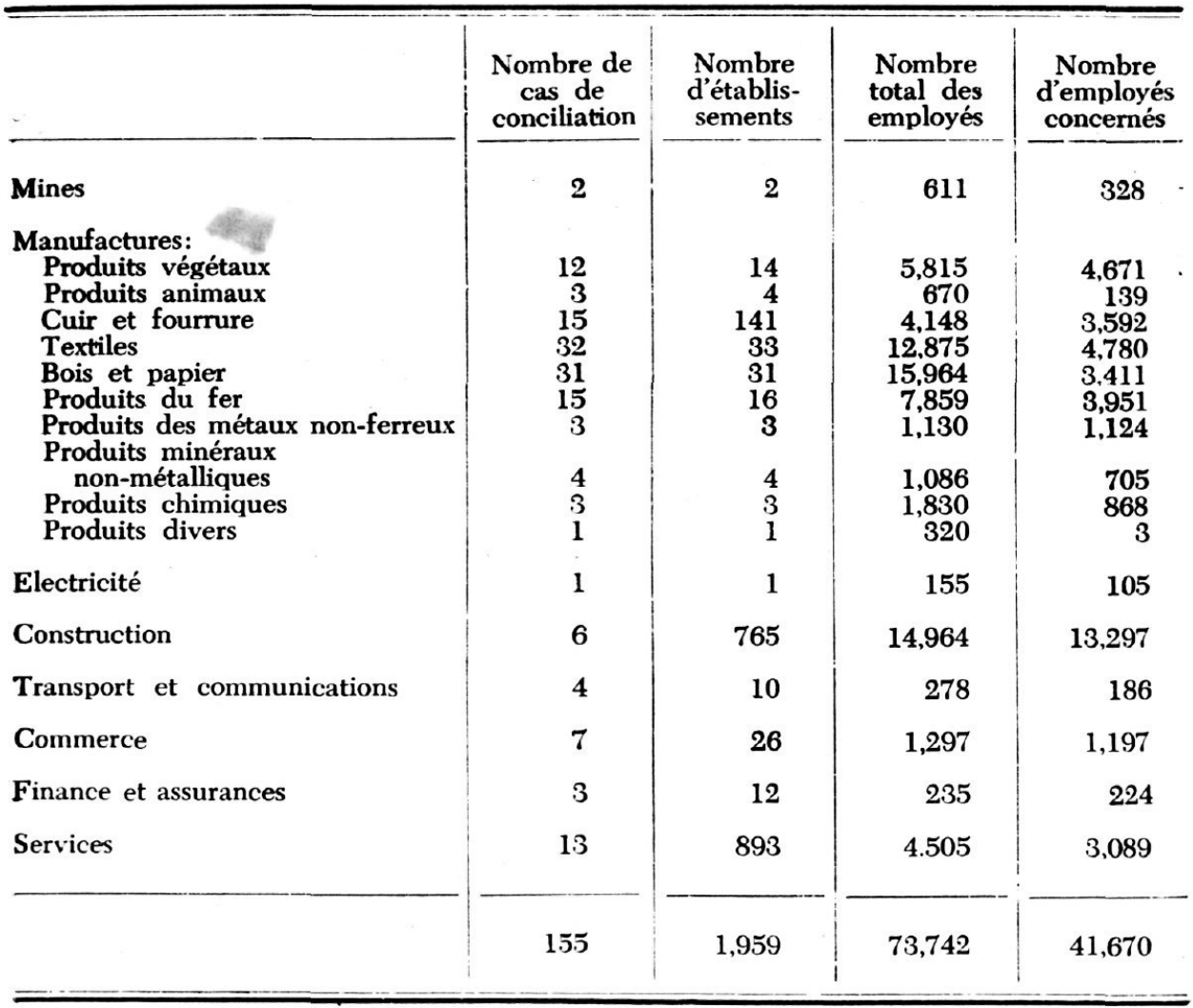

